\title{
Analysis of Tort Liability Related to Shared Bicycles--Taking OFO Shared Bicycles as an Example
}

\author{
Pengfei $\mathrm{Li}^{1}{ }^{1, \mathrm{a},{ }^{*}}$ \\ ${ }^{1}$ Law School, Shanxi University of Finance and Economics, Taiyuan030006, China. \\ a751559067@qq.com
}

\begin{abstract}
With the continuous advancement of urbanization, the concept of green travel has become more and more acceptable by the general public. The emergence of shared bicycles is the result of the deep development of the sharing economy, and it is also the result of the promotion and popularization of the green travel concept. Solving the last mile problem of city travel has become the development concept of shared bicycles. However, the issue of shared bicycles is also emerging: free parking, disorder management and infringement, etc. Among them, the issue of tort liability for shared bicycles is most prominent. There is infringement of the owner of the shared bicycle, the users, the third party, other than the users and the owner, etc. Therefore, how to identify the infringement of shared bicycles and determine the tort liability becomes a problem worthy of further investigation.
\end{abstract}

Keywords: OFO shared bicycle, tort liability, patent, trademark rights.

\section{Introduction}

Shared bicycle refers to a kind of bicycle sharing service provided by enterprises on campus, subway stations, bus stations, residential areas, commercial areas, public service areas, etc. It is a time-sharing lease mode. Shared bicycles are a new type of sharing economy. Since 2016, the shared bicycle market has grown rapidly across the country. So far, there are at least 24 shared bicycle brands including OFO, mobike, and Hellobike in China. It can be said that "the color left for the shared bicycle is not too much". However, the problems exposed behind the growth of shared bicycles cannot be ignored. First of all, the random parking of shared bicycles brings a lot of trouble to city management. Secondly, shared bicycle disorder management, paying attention to market development and neglecting supervision and management has become one of the incentives for sharing bicycle problems. Finally, around the shared bicycles, the phenomenon of a series of infringements has become the most extensive and complex problems. Firstly, there are diversity in the subjects associated with shared bicycles, including shared bicycle owners, shared bicycle users, and third parties other than the owners and users. Thus, the subject of infringement is complex. Secondly, the specific forms of infringement related to shared bicycles are also diverse. It can be expressed as a single infringement, joint infringement, and a combination of reasons and unintentional contact. Thus, the specific form of violations is complex. Finally, the infringement object has diversity, including property rights, public and private property ownership, life and health rights, patent rights, trademark rights, and even social public safety. Thus, the object of infringement is complex. Therefore, the determination of the infringement around the shared bicycle and the tort liability are very complicated and difficult. And the analysis of tort liability related to shared bicycles is extremely necessary and valuable. Why I wish to take the OFO as an example to analyze the tort liability, the reasons are following: Firstly, the OFO shared bicycle has a large market share which can get a lot of data. Secondly, the OFO entered the market earlier, which is relatively mature. Taking it as an example is easy to explore the overall drawbacks of the entire shared bicycle mode. Thirdly, the actual damage rate of OFO shared bicycles is higher. Take this as an example is easier to facilitate a more comprehensive and complete classification of specific types of infringement. 


\section{Constitutive Requirements of General Tort Liability}

\subsection{Illegal Behavior}

Illegal acts are acts or omissions committed by natural or legal persons in violation of the law. The illegal elements constitute an objective element of the tort liability, including the two elements of behavior and illegality. For behavior, behavior includes acts and omissions. For illegality, it includes violation of legal obligations, violation of legal prohibition regulations, deliberate violation of public order and good customs.

\subsection{Damage Fact}

Causality refers to the illegal connection of the infringer or the anecdotal facts of the possession, and the causal relationship between the facts and the damage caused by the fact that there is an objective connection between the latter and the latter caused by the former.

\subsection{Causal Relationship}

Subjective faults include intentionality and negligence. The so-called deliberate means that the perpetrator predicts the outcome of his or her actions and still want it to happen or to allow it to assume the subjective state of mind. Negligence refers to the subjective state of mind that the actor is acting on his or her own behavior, which should be foreseen and not foreseen or that is foreseen but credulously avoidable.

\section{Specific Infringements and Their Responsibilities}

\subsection{Infringement of the Owner of the Shared Bicycle and Its Responsibility}

\subsubsection{Destroy or Encroach on the Behavior of Shared Bicycles}

The damage to shared bicycles is mainly caused by damage to the seat, license plates, pedals, and locks. In these behaviors, the act of destroying the license plate, whether intentional or negligent, constitutes damage to the object, infringes the ownership of the owner of the shared bicycle, and shall be liable for damages. The destruction of the license plate causes the damage of QR code or the license plate number, which affects the normal use of the shared bicycle by others, and thus infringes the rights of the owner of the shared bicycle. Therefore, the act not only infringes the ownership of the owner of the shared bicycle, but also infringes upon the right to benefit, and should bear the tort liability for compensation for loss and restitution.

The behavior of encroaching on shared bicycles is mainly manifested in three aspects: concealing shared bicycles, destroying license plates and locking on private locks. For the behavior of concealing shared bicycles and destroying shared bicycle license plates, to OFO shared bicycles without GPS positioning system and static passwords, even if the behavior is subjectively only convenient for its own use and continues to be used for payment, the behavior still objectively produces the effect of illegal possession, which constitutes an infringement of the rights of income and property for the owners. Similarly, if it is for the purpose of illegal possession and is no longer paid for, the act constitutes theft. If the criminal responsibility standard is reached, the criminal liability of the perpetrator shall be investigated according to law. The act of privately locking and not paying for use, whether or not it destroys the lock, which is purposed for Illegal possession, constitutes theft. For the case of private locks, the use of paid use shall be deemed to be an infringement of the right of income to the owner. And the tort liability for the loss shall be compensated.

\subsubsection{Using the Shared Bicycle System Vulnerability to Violate the Lawful Rights and Interests of the Owner of the Shared Bicycle}

The use of shared bicycle which infringes the legitimate rights and interests of the owner is mainly manifested by the non-paid cracking of the static password that has been known, the use of the OFO which falsely reports the end of the trip, the behavior that does not end using after checkout, etc. 
These three types of behaviors are intentional in subjective faults, which constitute an infringement of the right to the owner of the shared bicycle, and should bear the tort liability for compensation for losses.

\subsubsection{Loss of Shared Bicycle Due to User Negligence}

Loss of shared bicycles due to user negligence, including forgetting to lock the car causing the bicycle lost and forgetting to lock the password after the lock, resulting in the loss of the bicycle., both of which are manifested as violations of the ownership of the shared bicycle owner. They should bear the responsibility for compensation and infringement damages.

\subsection{Infringement of the Shared Bicycle Users and Their Responsibilities}

\subsubsection{Damage to the User's Personal and Property Rights Due to the Shared Bicycles}

In this case, due to the OFO shared bicycle, the user's personal and property rights are damaged, which can be divided into two situations:

Firstly, although the OFO shared bicycle is faulty, the user's unchecked before use causes damage to their personal and property rights. According to the "OFO User Agreement", the user should inspect the vehicle before using the shared bicycle. If the user's personal property is lost due to the unchecked vehicle, the owner will not be liable for infringement.

Second, there is no fault in bicycle before use. When the user uses the vehicle and the property and property rights of the user are damaged due to the shared bicycles, the owner shall be liable for the infringement damages. In addition to the applicable tort liability determination rules, the legal liability for breach of contract liability can also be applied.

\subsubsection{The Infringement of the Users Due to a Third Person}

The reasons for the infringement of shared bicycle users due to third-party reasons are mainly divided into two cases: the third party destroys the OFO sharing bicycle and the user is damaged, and the third-person accident causes the shared bicycle user to be damaged.

In the first case, if the shared bicycle manager has fulfilled the maintenance obligation, the third party should independently bear the tort liability to the user. If the shared bicycle manager fails to fulfill the maintenance obligation, it may be combined with a third party to constitute a cause of infringement and a number of infringements of the innocent contact. The two shall bear the responsibility according to their own fault. In the second case, if the third party fails to cause the shared bicycle user to be damaged, if the shared bicycle manager performs the maintenance responsibility, the shared bicycle manager does not bear the tort liability. Otherwise, it also constitutes a reason for the infringement of several people who are unintentionally connected, and the shared bicycle manager and the third person bear the responsibility. In the case of a shared bicycle manager, owner, third party and negligence, the share of responsibility shall be determined according to the magnitude of the damage caused by the three.

\subsubsection{The Users Suffer the Damage of Personal Property Due to His Own Reasons}

The OFO shared bicycles are marked with the slogan "No bicycles for children under 12 years old" in the eye-catching area of the body and APP, and there are also tips on the safety of the vehicle in the APP. It can be seen that the shared bicycle manager has already fulfilled the obligation of reminding. Under such circumstances, the shared bicycle manager is not liable if the shared bicycle user is under 12 years of age, provides false information, engages in dangerous behavior, or engages in an accident for his own reasons.

\subsection{Infringement and Liability for Third Parties Other Than Shared Bicycle Owners and Users}

\subsubsection{Infringement of the Patent for the Shared Bicycle without Pile Concept}

The so-called "no pile concept" is "the bicycle rental operation system and method without fixed repayment point". The method or concept was applied for patent and was protected by patent rights as early as 2010. Therefore, after Yonganxing launched the shared bicycle, it was deeply involved in 
patent infringement disputes. According to Article 60 of the Patent Law: "The patent is enforced without the permission of the patentee, that is, the patent right is infringed". Therefore, if the patent is used without permission, it constitutes an infringement of the patentee. It shall bear the tort liability for stopping the infringement and compensating for the loss.

\subsubsection{Infringement of the Shared Bicycle Trademark}

OFO shared bicycles have a large share of the shared bicycle market, and it is inevitable to encounter trademark infringement. Taking the "QFQ" bicycle as an example, the trademark composition is similar to the OFO shared bicycle, and there is the possibility of disturbing the newly shared bicycle users. Thus, it may constitute trademark infringement of the OFO shared bicycle. Once a trademark infringement is constituted, it shall bear the tort liability including stopping the infringement and compensating for the loss.

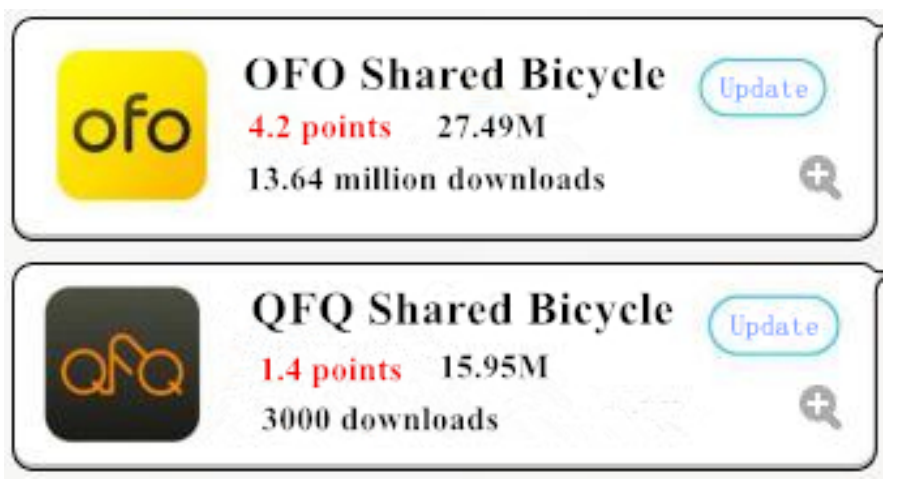

Fig 1. OFO shared bicycle and QFQ shared bicycle

\section{Regulatory Advice on Infringements Related to Shared Bicycles}

\subsection{Accelerate the Process of Real-name System Reform for Shared Bicycle Use}

The implementation of the shared bicycle real-name registration and use can not only fundamentally eliminate the possibility of children sharing the bicycle under the age of 12, increase the protection of children, reduce children's traffic accidents, and promote the status of uncivilized vehicles, which is conducive to promote the construction and improvement of the social credit system.

\subsection{Increase the Standardization of the Construction and Management System of Shared Bicycles}

To achieve this, we must improve the entry barrier of the shared bicycle market, change the state of disordered management of shared bicycles, promote the construction and application of industry operating standards, and accelerate the integration of shared bicycles into the scope of legal construction.

\subsection{Strengthen the Protection of Intellectual Property Rights in Shared Bicycles}

Strengthening the protection of intellectual property rights of shared bicycles is to do a good job in system regulation and construction of patent rights on the two roads of sharing bicycles from theory to market and from market to customers. At the same time, increasing the protection of trademark rights in the new economy, including shared bicycles, in order to achieve long-term, stable and harmonious development of shared bicycles.

\section{Conclusion}

Shared bicycles is a new thing that comes in line with the development of urbanization and the concept of green travel, it brings a series of problems besides convenience, it needs multi-faceted care from government, society, shared bicycle users, shared bicycle owners and others. It is not only 
necessary to share the bicycle owners to improve their services, but also to increase the regulation of the state and society. It is also necessary to shared bicycle users and other people to improve their personal qualities, obeying the law, and travelling in a civilized manner. Only then, shared bicycle will not become a kind of "illness."

\section{References}

[1]. Lexan Yang. Tort Liability Law [M]. Fudan University Press. 2016:89-94.

[2]. Bolin Dong, Hunan Wang. Intellectual Property Law - Patent Law [M]. Renmin University of China Press. 2014.

[3]. Shieh Shen, Hunan Wang. Intellectual Property Law - Trademark Law [M]. Renmin University of China Press. 2014. 